\title{
SEVERIDADE DA LIXA-GRANDE DO COQUEIRO-ANÃO E INCIDÊNCIA DE HIPERPARASITISMO EM PARNAMIRIM, RIO GRANDE DO NORTE ${ }^{1}$
}

\author{
RENATO AUGUSTO GOUVEIA DE CARVALHO², EGBERTO ARAÚJO3, ARTUR FRANCO BARRETO4, \\ GLEIBSON DIONÍZIO CARDOSO ${ }^{4}$, FERNANDES ANTONIO DE ALMEIDA ${ }^{3}$
}

\begin{abstract}
RESUMO - O estudo foi realizado em um coqueiral localizado na Estação Experimental Rammel Mesquita de Farias localizada no município de Parnamirim-RN, no período compreendido entre abril de 2000 e março de 2001 . Foram efetuadas observações quanto ao progresso (incidência e severidade) da lixa-grande do coqueiro causada pelo fungo Sphaerodothis acrocomiae e a ocorrência de hiperparasitismo sobre o agente causal da doença. Durante o período de observação, a incidência da lixa-grande foi igual a 100\%. O progresso da severidade apresentou tendências distintas de aumento entre os meses de abril e julho de 2000 e de decréscimo a partir do mês seguinte até março de 2001; da mesma forma, foram as tendências da incidência de hiperparasitismo. A severidade da lixa-grande e a incidência de hiperparasitas correlacionaram-se positiva e significativamente com as variáveis climáticas, precipitação pluviométrica e umidade relativa, e negativamente com as temperaturas.
\end{abstract}

Termo de Indexação: Epidemiologia, Hiperparasita, Cocos nucifera

\section{DISEASE SEVERITY AND INCIDENCE OF HIPERPARASITISM IN COCONUT ( Cocos nucifera L.) LEAVES AFFECTED BY THE FUNGI Sphaerodothis acrocomiae IN PARNAMIRIM, RIO GRANDE DO NORTE STATE, BRAZIL}

\begin{abstract}
The study was realized at the Experimental Station Rammel Mesquita Farias in the municipal district of Parnamirim, Rio Grande do Norte State, Brazil, in the period from April, 2000, to March, 2001. The observations were concerned to the disease progress (incidence and severity) on the coconut leaflets, as well as the occurrence of hiperparasitism on the causal agent. In all observations the disease incidence was equal to $100 \%$. The progress of the severity presented different tendencies: increasing - from April to July, 2000 and decreasing - from this month to Mach of 2001. In the same way were the tendencies of the hiperparasitism incidence. The disease severity and the hiperparasitism incidence were correlated positively and significantly with the climatic variables, pluviometric precipitation and relative humidity and, negatively with the temperatures. Index Terms: Disease, Epidemic, Coconut, Cocos nucifera
\end{abstract}

A cultura do coqueiro (Cocos nucifera L.) no Rio Grande do Norte está concentrada, principalmente, nas microrregiões Litoral Nordeste, Litoral Sul e Macaíba, sendo a mesma de importância social e econômica, pois situa-se entre as dez principais atividades agrícolas do Estado, ocupando mão-de-obra durante todo o ano.

No Rio Grande do Norte, as doenças do coqueiro, denominadas lixa-grande e lixa-pequena, causadas, respectivamente, pelos fungos Sphaerodothis acrocomiae (Montagne) Von Arx \& Muller e Phyllachora torrendiella (Batista) Subileau são importantes por provocarem a seca prematura das folhas inferiores e, como conseqüência, os cachos ficam sem apoio, quebrando-se, e os frutos caem antes do ponto de colheita. Para essas doenças, não existe recomendação de controle químico; no entanto, o controle biológico pelo emprego dos fungos Septofusidium elegantulum e Acremonium spp. tem sido realizado com sucesso (Madeira et al., 1998).

O presente trabalho foi realizado considerando a importância da lixa-grande, que vem diminuindo a produção do coqueiro no Estado do Rio Grande do Norte. O objetivo foi determinar as características (curvas) de progresso da doença e da incidência de hiperparasitismo sobre o agente causador da lixa-grande, bem como estabelecer associações entre essas ocorrências e as condições climáticas prevalecentes no período.

O estudo foi realizado no período entre abril de 2000 e março de 2001, em um coqueiral estabelecido na Estação Experimental Rammel Mesquita de Farias, da Empresa de Pesquisa Agropecuária do Rio Grande do Norte (EMPARN), no município de Parnamirim. Durante o período de observação, ocorreram precipitações pluviais, sendo os maiores valores registrados entre abril e setembro de 2000; a partir de outubro de 2000 a fevereiro de 2001, as chuvas foram menores que $50 \mathrm{~mm}$ mensais. A umidade relativa do ar, de abril até novembro de 2000, foi superior a $90 \%$, e no restante do período entre 80 e $85 \%$. Para as temperaturas máxima e mínima, as variações dos valores foram pequenas, sendo os valores dessas próximos a 30 e $20^{\circ} \mathrm{C}$, respectivamente.

Para a efetivação das amostragens referentes às observações epifitiológicas, foram demarcadas no coqueiral cinco parcelas de aproximadamente $1000 \mathrm{~m}^{2}$ (96 plantas), sendo, em intervalos de 30 dias, em cada parcela, coletados aleatoriamente 100 folíolos. Em seguida, determinavam-se a incidência (percentagem de folíolos atacados) e a severidade (extensão da doença) da lixa-grande, bem como a incidência de hiperparasitismo (percentagens de folíolos em que se observou o desenvolvimento de micélio dos fungos hiperparasitas Septofusidium elegantulum e Acremonio sp.).

A severidade da doença foi avaliada por meio de uma escala de notas elaborada, considerando-se o número de peritécios e o aspecto do limbo (manchas, secamento) da parte central do folíolo: $0=$ ausência de doença; 1 = de 1 a 5 peritécios situados ao lado da nervura central; $2=$ mais de 5 peritécios situados ao lado da nervura central e distribuídos pelo limbo (centro e margem); 3 = aparecimento de manchas escurecidas nas áreas do folíolo ocupadas pelos peritécios; 4 = aumento do número e tamanho dos peritécios em ambas as faces do folíolo, da mesma forma das áreas necrosadas; 5 = distribuição semelhante à anterior, porém com predominância de área foliar necrosada e seca. Para a expressão da severidade a partir dos dados obtidos, empregou-se o índice de Mackinney (Chester, 1950).

Os dados de severidade da doença e os de incidência de hiperparasitismo, transformados em $\ln \mathrm{x} / 1-\mathrm{x}$, foram pareados às datas de observação para a caracterização das curvas de progresso. Determinou-se também a correlação dessas variáveis entre si e com as variáveis climáticas (precipitação pluvial, umidade relativa e temperatura).

Em todos os meses de observação, os folíolos amostrados apresentaram os sintomas e os sinais da lixa-grande, semelhantes ao descrito por Warwick et al. (1988), sendo, portanto, a incidência sempre igual a 100\%. Quanto aos fungos hiperparasitas, nas observações sob

\footnotetext{
${ }^{1}$ (Trabalho 012/2003). Recebido: 23/12/2002. Aceito para publicação: 26/11/2003. Parte da Monografia do primeiro autor, apresentada à UFPB/CCA, para obtenção do título de Engenheiro Agrônomo.

${ }^{2} \mathrm{Eng}^{\circ} \mathrm{Agr}^{\circ}$ (UFPB/CCA, Areia) Vila Acadêmica, 58.397-000.

${ }^{3}$ Professores do Departamento de Fitotecnia-CCA/UFPB, Areia-PB. 58397-000. E-mails: egberto@cca.ufpb.br; agrof@bol.com.br.

${ }^{4}$ Eng $^{\circ}$ Agr ${ }^{\circ}$ Mestrando em Agronomia (UFPB/CCA, Areia) Vila Acadêmica, 58397-000. e-mail: gleibson75@hotmail.com.
} 
microscópio, constataram-se as estruturas características de Septofusidium elegantulum e Acremonio spp.

No período de maior precipitação, que compreendeu os meses de abril até julho de 2000, houve um aumento sucessivo da doença, mostrando-se uma tendência linear crescente da severidade (Figura 1A). A partir de agosto de 2000 até o final das observações, no mês de março de 2001, a tendência de progresso de severidade da lixa-grande foi decrescente (Figura 1A).

Observam-se, na Tabela 1, os coeficientes de correlação entre a severidade e as variáveis climáticas. Foram positivos e significativos aqueles referentes à associação da severidade com a precipitação pluvial e umidade relativa e, negativos, os referentes às temperaturas máxima e mínima. Esses resultados são decorrentes do que se observou quanto às tendências da severidade, apresentando uma taxa de infecção positiva no período em que a precipitação e umidade relativa apresentaram elevações sucessivas a cada mês, e taxa de infecção negativa, quando essas variáveis climáticas decresceram. Portanto, as condições de elevadas precipitações e umidade favoreceram a doença, corroborando o descrito por Mariano (1997).

Quanto ao efeito da temperatura no progresso da doença, as correlações negativas deveram-se mais às influências de precipitação e umidade relativa, pois, à medida que aumentavam, as temperaturas decresciam, conseqüentemente, essa relação inversa entre as variáveis climáticas reflete a severidade da lixa-grande.

A incidência de hiperparasitismo seguiu as tendências da severidade da lixa-grande do coqueiro (Figura 1B) de aumento até o mês de julho de 2000, e decréscimo a partir do mês seguinte até o final das observações.

Os coeficientes de correlação obtidos entre a incidência de hiperparasitismo e as variáveis climáticas foram da mesma forma que os da severidade da lixa-grande, positivos quanto à precipitação e umidade relativa, e negativos quanto às temperaturas (Tabela 1). Uma vez que as variáveis climáticas favoreceram o desenvolvimento da doença, conseqüentemente, disponibilizou-se mais substrato para as atividades dos hiperparasitas. Segundo Warwick (2000), o S. elegantulum, hiperparasita da lixa-grande do coqueiro, esporula abundantemente em condições de umidade relativa alta, sendo, conforme se observa na Tabela 1, a associação do hiperparasitismo com essa variável a que registrou maior coeficiente. Deve-se considerar a taxa de crescimento de hiperparasitismo, que foi, em termos de valores, maior que as taxas de infecção da doença (Figura 1A e 1B), o que pode significar um maior impacto positivo dos fatores climáticos sobre a atividade do hiperparasita do que sobre a doença.

Foi possível verificar que a incidência da lixa grande, em todas as observações, foi igual a $100 \%$, e o progresso da severidade da lixagrande do coqueiro apresentou tendências distintas: de elevação desde abril até julho de 2000 , e de decréscimo a partir do mês seguinte até o final das observações. Iguais tendências foram observadas para a incidência de hiperparasitismo. A severidade da lixa-grande e a incidência de hiperparasitismo correlacionaram-se positiva e significativamente com as variáveis climáticas precipitação e umidade relativa e, negativamente, com as temperaturas.
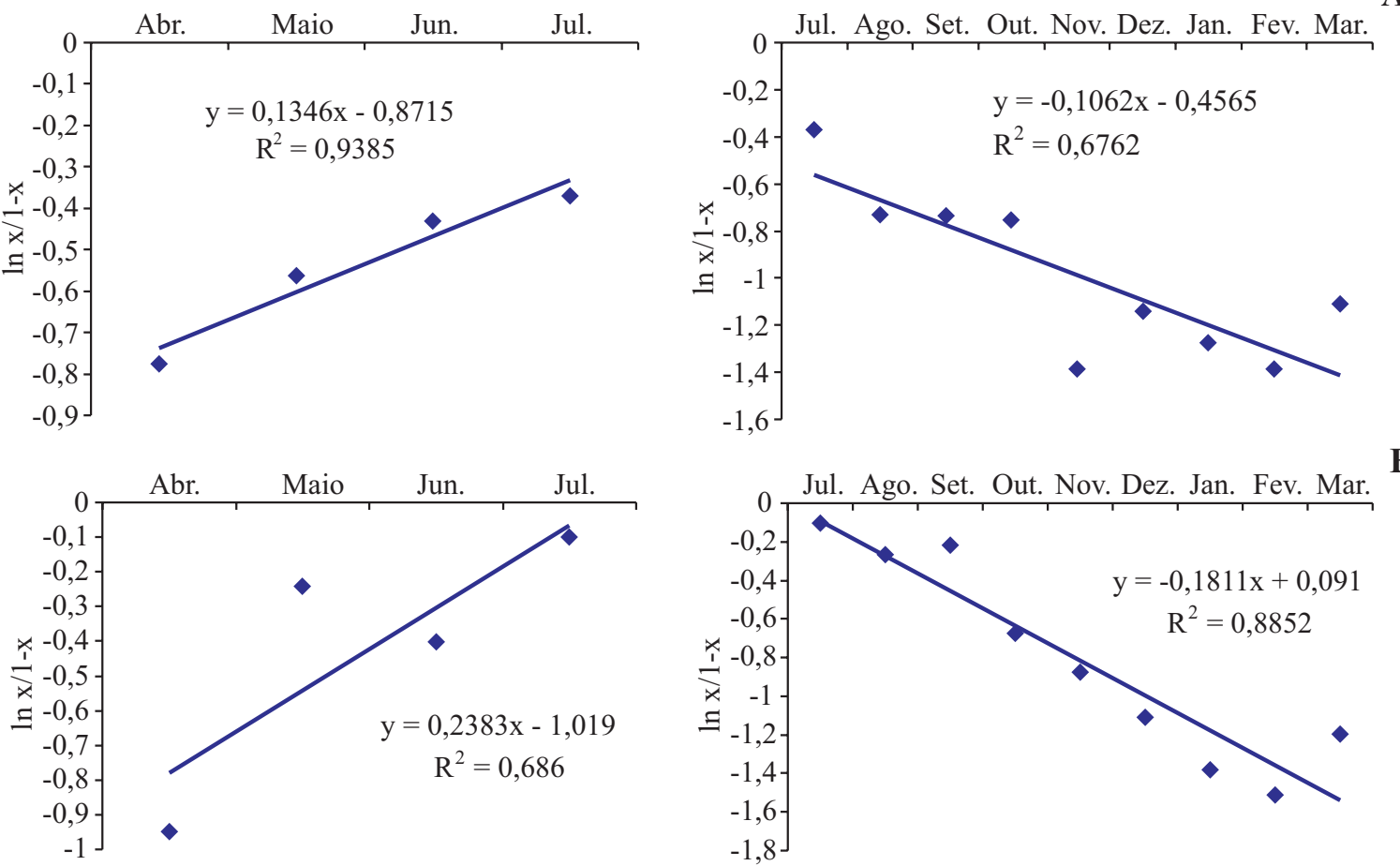

B

FIGURA 1 - Progresso da Severidade da lixa-grande do coqueiro (A) e da incidência de Hiperparasitismo (B). Parnamirim, RN, $2000-2001$.

TABELA 1 - Coeficientes de correlação da severidade da lixa-grande e da incidência de hiperparasitismo com as variáveis climáticas. Parnamirim$\mathrm{RN}, 2000-2001$.

\begin{tabular}{cccccc}
\hline & \multirow{2}{*}{ Hiper-parasitismo } & \multicolumn{4}{c}{ Variáveis climáticas } \\
\cline { 3 - 6 } & & Precipitação pluvial & Umidade relativa & Temperatura máxima & Temperatura mínima \\
\hline Severidade da doença & $0,865^{* *}$ & $0,90^{* *}$ & $0,85^{* *}$ & $-0,87^{* * *}$ & $-0,79^{* *}$ \\
Incidência hiperparasitismo & - & $0,81^{* *}$ & $0,85^{* *}$ & $-0,92^{* *}$ & $-0,90^{* *}$ \\
\hline
\end{tabular}

\footnotetext{
${ }^{* *}$ Coeficientes significativos a $1 \%$ de probabilidade
} 


\section{REFERÊNCIAS BIBLIOGRÁFICAS}

CHESTER, K.S. Plant disease losses: their appraisal and interpretetio. Plant Disease Reporter. Supplement 193: 190-362,1950.

MADEIRA, M.C.B; HOLANDA, J.S. de; GUEDES, F.X; OLIVEIRA, J.E. de. Coqueiro anão: da produção de mudas à colheita. Natal, RN.: EMPARN, 1998. 72p. (Documento, 26).

MARIANO, R.L.R. Doenças do coqueiro (Cocos nucifera L.) In: KIMATI, H; AMORIM, L.; BERGAMIM FILHO, A. et al. Lixa pequena e lixa grande. Manual de fitopatologia 3. ed. São Paulo-SP: Agronômica Ceres, 1997. v.2.p.301-302. 1997.

WARWICK, D.R.N. Influência dos fitopatógenos na cadeia produtiva do coqueiro. Fitopatologia Brasileira, Suplemento, v.25, p.296-302, Ago. 2000.

WARWICK, D.R.N.; LEAL, E. C.; RAM, C. Doenças do coqueiro. In: FERREIRA, J.M.; WARWICK, D.R.N.; SIQUEIRA. L.A. Eds. A cultura do coqueiro no Brasil. 2. ed. Aracaju: EMBRAPA-SPI, 1998. p.269-289. 